EGU2020-6006, updated on 17 Dec 2020

https://doi.org/10.5194/egusphere-egu2020-6006

EGU General Assembly 2020

(c) Author(s) 2020. This work is distributed under

the Creative Commons Attribution 4.0 License.

\title{
Microseismicity constrains on the lithospheric structure at the ridge-transform intersection at the Romanche Transform Fault and Mid-Atlantic Ridge
}

\author{
Zhiteng Yu${ }^{1,2}$, Satish C. Singh ${ }^{1,3}$, Emma Gregory ${ }^{1}$, Wayne Crawford ${ }^{1}$, Marcia Maia ${ }^{4}$, and Daniele \\ Brunelli $i^{5,6}$ \\ ${ }^{1}$ Equipe de Géosciences Marines, Institut de Physique du Globe de Paris (CNRS, Paris Diderot, Université de Paris), Paris, \\ France \\ ${ }^{2}$ Key Laboratory of Submarine Geosciences, State Oceanic Administration, Second Institute of Oceanography, Ministry of \\ Natural Resources, Hangzhou, China \\ ${ }^{3}$ Earth Observatory of Singapore, Nanyang Technological University, Singapore \\ ${ }^{4}$ CNRS-Université de Bretagne Occidentale, IUEM, France \\ ${ }^{5}$ Università di Modena e Reggio Emilia, Modena, Italy \\ ${ }^{6}$ Geology \& Geophysics, WHOI, Whoods Hole, MA, USA
}

The Romanche Transform Fault (TF) in the equatorial Atlantic Ocean is the largest oceanic transform fault on Earth, offsetting the slow-spreading $(2 \mathrm{~cm} / \mathrm{yr})$ Mid-Atlantic Ridge (MAR) by 900-km and producing a maximum age contrast at the Ridge-Transform Intersection (RTI) of 45 Myr. This offset could cause a large thermal variation in the lithosphere around the RTI, but it is not known how this thermal variation would manifest itself. Here we present a 21 -day-long microearthquake study using a temporary deployment of 19 ocean-bottom seismometers (OBSs) during the 2019 SMARTIES cruise. 1363 earthquakes were detected on at least three OBSs and 622 could be located, of which 351 have high location accuracy (mean semi-major-axis of $3.9 \mathrm{~km}$ ).

Linear (HYPOSAT) and non-linear (NonLinLoc) location algorithms reveal a similar earthquake distribution. Two event groups cluster at depths of 1) $0 \mathrm{~km}$ to $\sim 18 \mathrm{~km}$ and 2) $\sim 20 \mathrm{~km}$ to $30 \mathrm{~km}$. Along the Romanche TF, micro-earthquakes are located beneath the southern border of the $30 \mathrm{~km}$ wide transform valley; no events are observed beneath the central or northern sections of the valley. These events' depths increase rapidly and linearly from a few $\mathrm{km}$ at the RTI to $30 \mathrm{~km}$ at 40 $\mathrm{km}$ along the transform fault, indicating a rapid increase in the thickness of the seismogenic zone (and lithosphere) along the transform fault. The presence of earthquakes on the southern border of the transform fault, which is younger and hence warmer, suggests that these events, and hence the seismogenic zone, follow an isotherm separating the brittle-ductile boundary. The absence of seismicity beneath the centre and northern boundary of the transform fault could be due to a much colder lithosphere and hence deeper ductile-brittle boundary.

An aseismic gap exists beneath the pull-apart basin observed on bathymetry data. Beneath the $\mathrm{RTI}$, earthquakes mainly occur in the $0-18 \mathrm{~km}$ depth range. Eight well-constrained focal mechanisms, derived from P-wave polarities, suggest that strike-slip faulting dominates along the 
transform fault. Normal faults are also observed, which may be attributed to an active detachment fault or pull-apart basin formation.

From the RTI to the tip of the southern MAR segment, micro-earthquakes show an undulating focal depth distribution from north to south. They can be summarized into three clustering groups: the RTI, the $16.6^{\circ} \mathrm{W}$ group, and the $16.2^{\circ} \mathrm{W}$ group. Micro-earthquakes beneath the MAR are mainly located in the axial valley. Events in the $16.6^{\circ} \mathrm{W}$ group mainly occur in the mantle at depths of $12-20 \mathrm{~km}$, whereas those in the $16.2^{\circ} \mathrm{W}$ group are located at shallow depths of $2-12 \mathrm{~km}$, which is similar to that observed along other slow-spreading Mid-Ocean Ridges. This evidence indicates that there are significant variations in the along-axis thermal structure of the lithosphere along the rift axis.

ZY acknowledges the China Postdoctoral Science Foundation (2019M652041, BX20180080); DB acknowledges funding PRIN2017KY5ZX8. 